\title{
Private Equity gera valor ao acionista? Uma análise comparativa de retorno e risco após o IPO
}

\author{
(Does Private Equity generate Shareholder Value? A comparative \\ analysis of the return after the IPO)
}

\author{
Rogério Paulucci Mauad* \\ Denis Forte $^{* *}$
}

\begin{abstract}
Resumo
O crescimento vigoroso da indústria de Private Equity no mundo gerou questões fundamentais, como por exemplo explicar se as empresas abertas previamente investidas por estes gestores geram retornos reais aos seus acionistas, após o evento do IPO. Pouco se analisou, entretanto, sobre o risco dessas novas empresas. A contribuição deste artigo visa suprir especificamente essa lacuna com a inovação na ferramenta metodológica. A metodologia Wealth Relative Buy-andHold foi ajustada pelo seu risco idiossincrático, em cima da base de ofertas públicas realizadas na BM\&FBovespa entre 2004-2014. Desconsiderando risco, os resultados sugerem o reconhecimento pelo mercado do prêmio de valor da gestão dos fundos nas empresas investidas, com retornos médios $36 \%$ superiores aos das empresas não-investidas, nos cinco primeiros anos pós-IPO. Ao incluir o ajustamento pelo risco, a presença de um fundo Private Equity não se mostra mais significante no retorno relativo das ações. A sugestão dos autores é que se testem amostras diferentes, períodos diferentes e artigos passados para verificar se as conclusões de geração de resultado se mantêm.
\end{abstract}

Palavras-chaves: Private Equity, Retorno relativo, Risco, IPO.

Códigos JEL: C580; G110; G120

Submetido em 18 de dezembro de 2015. Reformulado em 06 de março de 2017. Aceito em 29 de março de 2017. Publicado on-line em 18 de julho de 2017. O artigo foi avaliado segundo o processo de duplo anonimato além de ser avaliado pelo editor. Editor responsável: Paulo Terra.

* Universidade Presbiteriana Mackenzie e FMU, São Paulo, SP, Brasil. E-mail: rogeriomauad51@gmail.com

${ }^{* *}$ Universidade Presbiteriana Mackenzie e FMU, São Paulo, SP, Brasil. E-mail: denisfortebr@yahoo.com.br

Rev. Bras. Finanças (Online), Rio de Janeiro, Vol. 15, No. 1, March 2017, pp. 25-58 ISSN 1679-0731, ISSN online 1984-5146

(C)2017 Sociedade Brasileira de Finanças, under a Creative Commons Attribution 3.0 license http://creativecommons.org/licenses/by/3.0 


\begin{abstract}
The vigorous growth of Private Equity Industry in the world generated basic questions; as for example how to explain if companies previously invested by Private Equity generate real returns for its shareholders after the IPO event. Few studies analyzed, however, the risk of these new companies. The contribution of this paper meet specifically this gap with this innovation in the methodological tool. The Wealth Relative Methodology Buy-and-hold was adjusted by its idiosyncratic risk over the public offerings base on the BM\&FBovespa between 2004-2014. When risk is not considered, the results suggest a value premium on the management of Private Equity previously invested, with average returns $36 \%$ higher than those companies without this kind of management in the first five years post IPO. However, in the presence of risk adjustment, the previous participation of a Private Equity Fund is not significant in the returns anymore. The suggestion of the authors is that other samples, different periods, and past papers run this methodology to check if the previously conclusions still stands up.
\end{abstract}

Keywords: Private Equity, Wealth Relative Return, Risk, IPO.

\title{
1. Introdução
}

A partir de 2004, o Brasil começou a receber um intenso fluxo de capital estrangeiro, beneficiado pelas baixas taxas de juros internacionais e pelo chamado boom das economias emergentes, favorecendo a reabertura do mercado nacional para os Initial Public Ofering (IPO), ofertas públicas iniciais de ações realizadas por empresas de capital fechado. Desde maio de 2004 até junho de 2015 foram realizados 152 IPOs na Bolsa de Valores de São Paulo (BM\&FBovespa) envolvendo uma quantia aproximada de R \$ 152 bilhões, captada pelas novas empresas.

Os recentes estudos nacionais de finanças (Tavares e Minardi, 2010; Silva e Famá, 2011; Minardi et al, 2013; Bastos et al, 2016) tem dedicado especial atenção aos retornos pós-IPO de empresas brasileiras previamente investidas por fundos de Private Equity (PE), comparando-os aos de outras empresas sem este tipo de investimento prévio. Este artigo analisa, a partir de estudo de evento, se as empresas nacionais previamente investidas por fundos PE, cujos IPOs realizaram-se a partir de maio de 2004, obtiveram retornos relativos superiores em suas ações, se comparadas às demais empresas (NPE).

Os principais estudos da área até então concentram-se em analisar o retorno anormal acumulado da ação da empresa no período pós-IPO, comparando os dois grupos $\mathrm{PE}$ e NPE. Contudo, não ponderam o 
desempenho da ação pelo seu risco idiossincrático, obtendo conclusões, em muito similares, sobre as influências dos fundos PE em tais performances de mercado. A contribuição desta pesquisa ao tema e avanço em sua fronteira de conhecimento reside na ponderação do retorno relativo do ativo, calculado como uma ratio em face de seu benchmark, pelo seu risco individual, representado pelo coeficiente beta.

O tema apresenta relevância, pois os investimentos realizados por fundos PE em empresas brasileiras atraem gestoras nacionais $\mathrm{e}$ estrangeiras, as quais aportam recursos substanciais, fomentando o mercado de capitais nacional. Os IPOs realizados no período de estudo envolveram dezenas de milhares de investidores, os quais aplicaram seus recursos em novas ações, no intuito de obterem retornos satisfatórios. Abre-se, portanto, a oportunidade com este estudo, de explicar se a relação retorno-risco das ações da empresa após o IPO pode ser influenciada pela presença de um fundo PE na estrutura de capital. Em suma, o maior risco individual de uma ação estreante no mercado foi recompensado com o maior retorno para os investidores? Caso positivo, os fundos PE tiveram papel relevante em reduzir os riscos individuais da ação e/ou aumentar os retornos efetivos? Estas são, em síntese, as principais questões ainda não elucidadas na literatura nacional, que este artigo visa responder, contribuindo para o alargamento na fronteira do conhecimento.

Como inovação, acrescenta-se a utilização do coeficiente beta, como proxy ao risco do ativo, à metodologia Wealth Relative Buy-and-Hold (WRBH), desenvolvida por Ritter (1991), Brav e Gompers (1997) e Cao e Lerner (2009). Neste sentido, testa-se a hipótese da gestão prévia de um fundo PE na empresa, antes da abertura de capital, se mostrar estatisticamente significante para explicar os retornos relativos aos investidores após o IPO, quando analisado também o risco idiossincrático de cada ativo. Este é o gap teórico que o presente artigo busca elucidar, pois pondera à análise do retorno individual de cada uma das ações de empresas brasileiras que abriram capital, a partir de 2004, o seu índice de sensibilidade em relação ao índice de referência.

Testam-se as seguintes hipóteses: H1 - as ações das empresas previamente investidas por fundos $\mathrm{PE}$ oferecem um retorno superior se comparadas às ações de empresas não-investidas, nos períodos subsequentes ao IPO, a partir de 2004, quando não considerado o risco individual do ativo; $\mathrm{H} 2$ - as ações das empresas previamente investidas por fundos $\mathrm{PE}$ oferecem um retorno superior se comparadas às ações de empresas não-investidas, nos períodos subsequentes ao IPO, quando considerado também o risco individual do ativo, pelo acréscimo do 
coeficiente beta à formula WRBH; H3 - a presença de um fundo PE entre os acionistas da empresa antes do IPO é estatisticamente significante para explicar os retornos relativos da ação pós-IPO, não ponderados pelo risco individual do ativo e; $\mathrm{H} 4$ - a presença de um fundo PE entre os acionistas da empresa antes do IPO é estatisticamente significante para explicar os retornos relativos da ação pós-IPO, quando ponderados pelo risco individual do ativo. Segundo metodologia WRBH, todos os retornos relativos anuais, ponderados ou não pelo risco individual, foram calculados em face do Índice Bovespa, considerado benchmark do mercado nacional. A escolha deste índice de referência segue a metodologia já tradicional na recente literatura nacional (Silva e Famá, 2011 e Minardi et al, 2013).

As limitações deste estudo encontram-se no tamanho da amostra e no espaço temporal pequenos, visto que, excluídas as que não se adequaram aos critérios da pesquisa, contam apenas 136 empresas que abriram capital em um período de tempo exíguo de dez anos de dados.

$\mathrm{O}$ artigo está estruturado da seguinte forma: no capítulo 2, revisa-se a literatura acerca do tema; no capítulo 3, expõe-se a metodologia do cálculo dos retornos relativos simples e ponderados pelo risco da ação, com uso da fórmula WRBH; no capítulo 4, apresentam-se os resultados obtidos e no capítulo 5, as conclusões finais do artigo.

\section{Revisão de literatura}

\subsection{Private Equity (PE) e geração de valor na empresa investida: Governança Corporativa, profissionalismo da gestão e networking}

O objetivo de um fundo PE é propiciar retorno superior ao capital de seus investidores, pela geração de valor na empresa investida, durante o prazo total do investimento (Brav e Gompers, 1997; Gompers e Lerner, 2001). A estratégia de investimento é baseada em aportes de capital, financiamento e técnicas de gestão diferenciadas, com práticas de governança corporativa.

Gompers e Lerner (2001) destacam que os fundos PE acrescentam valor aos seus investimentos de portfólio, não apenas pelo aporte financeiro, mas também através do desenvolvimento de um plano de negócios, networking, recursos humanos e intenso monitoramento da atividade no período pós-investimento. Mesma conclusão está no artigo de Morsfield e Tan (2006), para quem os fundos agregam valor com injeção de capital, além de serviços e expertise. Axelson et al (2009) pontuam que 
a presença dos fundos PE na estrutura societária minimiza os conflitos internos de agência nas empresas investidas.

Em consonância, Engel (2002) estuda o impacto dos fundos PE no crescimento das empresas alemãs e destaca seu papel importante no financiamento e desenvolvimento de pequenas empresas, possibilitando um impacto positivo em suas taxas de crescimento. Conclusão similar é obtida por Scholes et al (2009), os quais revelam terem os fundos PE forte impacto na estratégia de desenvolvimento de empresas familiares, favorecendo aquelas com boas perspectivas ainda não realizadas e um grande potencial de crescimento, a ser obtido mediante injeção de recursos e de novas técnicas de gestão.

Folta e Janney (2004) observam que a presença de um fundo PE na empresa investida serve como atenuante na ocorrência de assimetrias de informação, através de monitoramento do investimento ex post, trazendo benefícios de longo prazo aos acionistas e à empresa. Neste sentido, os ganhos aos acionistas propiciados pela adoção de práticas de Governança Corporativa e melhor acesso a capitais, também são observados por Kaiser e Westarp (2010) os quais concluem serem os fundos PE responsáveis pela redução na assimetria de informações, pois se especializam em due diligence ao promoverem incentivos para a transparência da gestão, gerando mais confiança nos demais investidores e reconhecimento do mercado. Hochberg (2012), em conclusão análoga, destaca como ganho de Governança Corporativa, a maior presença de Conselhos de Administração independentes, entre as empresas investidas por fundos PE.

De acordo com a Associação Brasileira de Private Equity e Venture Capital (ABVCAP), a gestão de um fundo PE agrega recursos e conhecimentos à empresa, visando seu crescimento acelerado e sustentabilidade. A presença de um fundo PE na administração profissionaliza e maximiza o valor da empresa, aplica regras de governança corporativa, aprimora a qualidade da gestão, com melhoras na credibilidade e na imagem institucional da companhia. Segundo a ABVCAP, a participação de um fundo $\mathrm{PE}$ abre as portas de um relacionamento qualificado no mercado onde a empresa atua, tornando-a competitiva, preparando-a para atuar no mercado global. Neste sentido, Gompers (1995), Brav e Gompers (1997) e Tavares e Minardi (2010) concluem que os fundos $\mathrm{PE}$ geram valor às companhias investidas, preparando-as para uma futura abertura de capital. 
Os próximos subitens analisarão o comportamento das ações das empresas investidas por fundos PE, a partir do IPO, em seus componentes de retorno (underpricing e desempenho) e risco.

\subsection{Underpricing das ações de empresas investidas por fundos $\mathbf{P E}$}

Chambers e Dimson (2009), estudam as ofertas públicas de empresas britânicas em um período de sete décadas e definem o underpricing como o retorno positivo do primeiro dia de negociações na ação da empresa, após a precificação de seu IPO. Quanto maior a valorização da ação da empresa no primeiro dia de negociação no mercado secundário, em relação ao preço obtido no lançamento da oferta pública, maior será o underpricing. Minardi et al (2015) classificam-no como "money left on the table", ou dinheiro deixado na mesa. Portanto, é um custo indireto para a empresa, pois uma parte potencial de recursos deixa de ser arrecadada por ocasião do IPO, recursos estes que poderiam ser direcionados inteiramente à companhia, no caso de uma emissão apenas primária, ou aos acionistas originais, em caso de oferta secundária.

Diversos trabalhos encontram uma correlação forte entre o menor underpricing das ações das empresas investidas por fundos PE e a adoção de regras de Governança Corporativa em período anterior à oferta pública. Barry, Muscarella, Peavey e Vetsuypens (1990), analisam 1.556 ofertas públicas no período 1978-87 e concluem que as ações de empresas investidas por fundos PE possuem menor underpricing se comparadas às não-investidas (NPE). Possíveis razões elencadas são o monitoramento intenso dos investimentos pelos fundos, pois ocupam assentos nos conselhos de administração, e frequentemente mantém posições significativas nas empresas, após o IPO e a redução na assimetria de informações aos investidores.

Megginson e Weiss (1991) encontram resultados semelhantes, destacando ser a presença dos fundos PE entre os acionistas, um certificado de qualidade na gestão das empresas, reduzindo a assimetria de informações e gerando um underpricing menor. Neste sentido, para Brav e Gompers (1997), se as empresas financiadas por fundos PE são melhores, na média, o mercado deve então incorporar estas expectativas positivas no preço da oferta, corroborando para um menor underpricing nas ações.

Para Ellul e Pagano (2006) o underpricing decorre, principalmente, de assimetria de informações sobre a empresa. A presença de um fundo PE entre os acionistas tende a reduzir as assimetrias de informações, com a 
adoção de normas de Governança Corporativa e gerar, na média, um underpricing menor. Em consonância, para Leone et al (2007), os procedimentos de disclosure adotados pelas empresas antes do IPO reduzem a incerteza ex ante, melhorando a precificação das ações antes da estreia no mercado secundário e diminuindo a ocorrência de underpricing de um dia. Conclusão similar obtém Ferrari e Minardi (2010) que encontram evidências de menor underpricing nas ofertas públicas brasileiras entre as empresas investidas por fundos PE devido, principalmente, à redução nas assimetrias de informação.

Consoante Chemmanur e Loutskina (2005), as empresas previamente investidas por fundos PE são muito mais valorizadas se comparadas às $\mathrm{NPE}$, por ocasião do IPO, frequentemente gerando um underpricing menor em suas ações. A boa reputação do fundo investidor é essencial para a melhor precificação da ação, pois são associados a underwriters e investidores institucionais mais sólidos. Em consonância, Levis (2011), usando uma amostra de IPOs realizados no Reino Unido no período 19922005, encontra underprincing menor nas ações das empresas investidas por fundos PE, se comparadas às NPE.

Contudo destaca-se que há estudos os quais apontam maior underpricing em ações de empresas PE se comparadas às NPE, como em Lee e Wahal (2002), principalmente no período conhecido como "bolha da internet" entre 1999-2000. A pluralidade de conclusões é saudável e contribui para o aperfeiçoamento da pesquisa empírica. Para Lee e Wahal (2002), um grande underpricing representa um custo real e uma transferência de riqueza dos antigos acionistas, entre eles os fundos PE presentes na composição acionária antes do IPO, para os novos acionistas.

\subsection{Desempenho das ações das empresas investidas por fundos PE no período pós-IPO}

A literatura de finanças dedica potencial e crescente interesse ao estudo dos retornos das ações de empresas investidas por fundos PE em seus primeiros anos pós-IPO, comparando-os com os retornos de ações das empresas NPE.

Jain e Kini (1995), analisam uma amostra de empresas cujos IPOs se realizaram no período 1976-88, e encontram uma relação positiva entre a presença dos fundos PE e a geração de valor na empresa investida, no período pós-IPO, através do crescimento dos fluxos de caixa e das vendas. O modelo desenvolvido utiliza como variáveis o logaritmo natural do 
tamanho da oferta, market-to-book, razão preço/lucro (price-earnings ratio), indicadores como o crescimento no fluxo de caixa operacional e crescimento no operating return-on-assets. Os autores não utilizam uma medida de risco de mercado para ação em seu período pós-IPO, da forma como utilizada nesta pesquisa. O mercado reconhece o potencial dos fundos PE em gerar valor aos acionistas, decorrente de sua capacidade de monitorar e guiar as empresas, em seus primeiros anos de mercado aberto. Em consequência, suas ações exibem, na média, melhor retorno. No mesmo sentido, $\mathrm{O}$ estudo de Morsfield e Tan (2006), utiliza como variáveis de controle a reputação do underwriter do IPO, indicadores de performance do fundo, crescimento nas vendas, dívidas de longo prazo e valor de mercado sem, contudo, mensurar o risco individual da ação pósIPO. Com base em uma amostra de 2630 empresas norte-americanas cujos IPOs ocorreram no período 1983-2001, aponta que o monitoramento por parte dos fundos PE nas empresas explica, em parte, os retornos superiores no valor das ações, em períodos subsequentes à oferta pública.

Brav e Gompers (1997) utilizam a fórmula do Wealth Relative Buyand-Hold (WRBH) para apurar os retornos pós-IPO, empregada neste artigo, e encontram retorno superior nas ações de empresas investidas por fundos PE em relação às demais, em período de cinco anos, apenas quando os retornos são ponderados igualmente, ou seja, o peso de cada retorno da amostra é o mesmo. Quando o retorno é ponderado por valor de mercado, as diferenças de desempenho entre os dois grupos se reduz. Cao e Lerner (2009) também utilizam a fórmula WRBH, e encontram retornos fortes em empresas reverse leveraged buyout (RLBO) investidas por fundos $\mathrm{PE}$, no primeiro, quarto e quinto ano após o IPO. Destaca-se que Brav e Gompers (1997) ponderam as empresas pelo tamanho e book-to-market, sem precisamente considerar o risco individual da ação face o mercado, especificamente considerado neste artigo com o uso do beta.

O horizonte temporal dos retornos superiores após a oferta pública das empresas investidas por fundos PE é estudado em diversos trabalhos. Ogden et al (2003), encontram retornos superiores nas ações destas empresas nos períodos de uma semana, um mês, seis meses e um ano após o IPO. Segundo Chemmanur e Loutskina (2005), as quais utilizam múltiplos contábeis e de mercado, além da reputação individual de cada fundo PE para medir a influência destes nos retornos pós-IPO, este desempenho superior inicialmente constatado, tende a se dissipar ao longo dos anos, praticamente desaparecendo cerca de três anos após a oferta pública. $\mathrm{O}$ foco da pesquisa concentra-se em dados contábeis, v.g., a razão 
EBITDA/vendas e não no risco idiossincrático do ativo nos períodos pósIPO.

Também neste sentido, Levis (2011), estudando as ofertas públicas no Reino Unido com o uso de buy-and-hold abnormal return (BHAR) e utilizando quatro variáveis, FTSE All-share index, capitalização de mercado, setor da indústria e book-to-market, encontra evidências de maior lucratividade e retornos superiores em empresas investidas por fundos PE, no período de 36 meses após o IPO, comparando-as às demais empresas e ao mercado como um todo. Não há no modelo uma variável que mensure o risco individual da ação no mercado, consoante considerado neste artigo.

No Brasil, Tavares e Minardi (2010) estudam o desempenho de 53 empresas cujos IPOs se realizaram entre janeiro de 2004 e fevereiro de 2007, através da técnica do cumulative abnormal return (CAR), no prazo de um ano e concluem que a presença de um fundo PE na empresa está fortemente correlacionada com o retorno superior obtido no prazo de um ano pós-IPO. Silva e Famá (2011) também utilizam o CAR e observam relevantes perdas nas carteiras de ações pós-IPO (long-run underperformance) sem, contudo, separá-las em PE e NPE e mensurar o risco individual do ativo. Minardi et al (2013), examinam o desempenho dos IPOs realizados no período 2004-2008 e encontram evidências de um retorno de um ano superior em ações de empresas investidas por fundos PE se comparadas às demais, sejam estes retornos simples ou ponderados pela capitalização de mercado da empresa. Bastos et al (2016) observam retorno superior em empresas investidas por fundos $\mathrm{PE}$ em apenas quatro setores, consumo, imóveis, saúde e utilidade pública, quando utilizada a metodologia buy-and-hold e o benchmark setorial, ao invés do Índice Bovespa.

\subsection{O risco individual de cada ação}

A contribuição deste artigo está em levar o estudo para além da simples análise dos retornos das ações após a oferta pública, acrescentando à análise de cada ativo, o seu risco idiossincrático. Diversos artigos estudam os desempenhos das ações brasileiras pós-IPO, a partir do seu CAR, sem tecer considerações acerca do risco individual da ação frente ao benchmark. (Tavares e Minardi, 2010; Minardi et al, 2013; Bastos et al, 2016). Alguns autores como Brav e Gompers (1997) ponderam os retornos dos ativos por alguns dos fatores de Fama e French (1993), tais como capitalização de mercado e market-to-book. 
Como proxy para o risco idiossincrático, utiliza-se o coeficiente Beta $(\beta)$, que mede a sensibilidade de um título a movimentos da carteira de mercado (Ross et al, 2010 e Brealey et al, 2014). A partir dos conceitos de beta do ativo, os artigos seminais de Sharpe (1964) e Littner (1965) derivam a equação Capital Asset Price Model (CAPM), a qual estabelece que o retorno esperado de um ativo está linearmente correlacionado à covariância deste mesmo título com a carteira de mercado, dividido pela variância da carteira de mercado. A equação CAPM reflete o risco sistemático de um ativo pelo seu coeficiente beta (Assaf, 2015). A carteira de mercado, cujo beta é igual a 1, possui apenas o risco sistemático, pois o risco não sistemático foi eliminado pela diversificação dos ativos (ASSAF, 2015).

Segundo Bodie, Kane e Marcus (2014), o prêmio pelo risco dos ativos individuais é proporcional ao prêmio pelo risco sobre a carteira de mercado e ao coeficiente beta do título relativo à carteira de mercado. Brealey, Myers e Allen (2014) destacam que ações com beta maior que 1,00 amplificam os movimentos de mercado, enquanto aquelas com beta entre 0 e 1,00 caminham na mesma direção do mercado, porém sem a mesma intensidade. Kerins et al (2004) utilizam o beta como proxy ao risco e correlação com o mercado e asseveram que o trade-off de risco-retorno do CAPM é o custo de oportunidade de um portfólio não-diversificado. Desta forma, o retorno do ativo em relação ao prêmio de risco da carteira do mercado, representado pelo retorno esperado do benchmark menos o retorno risk-free, está relacionado ao seu coeficiente beta. O beta é amplamente utilizado pelo mercado para a avaliação de riscos de ativos individuais e composição de carteiras. Este é o gap teórico que o presente estudo visa preencher, pois pondera à análise do retorno de ações de empresas brasileiras que abriram capital, a partir de 2004, o seu índice de sensibilidade em relação ao benchmark, de modo a explicar se a prévia gestão de um fundo PE é estatisticamente significante.

\section{Metodologia}

\subsection{Definição dos períodos de estudo e base de dados utilizada}

Os 136 IPOs que compõem a amostra foram realizados no período de 2004 até 2014. As empresas encontram-se divididas em dois grupos, empresas investidas por fundos PE e as demais (NPE). Com os dados coletados nas bases Bloomberg e Economática, calculam-se os retornos relativos das ações, simples e ajustados pelo risco individual, nos períodos 
de 1 até 5 anos após o IPO. Usa-se a precificação da ação no dia anterior ao início das negociações, também conhecida como preço de lançamento, como ponto inicial para determinar os retornos relativos anuais e também os retornos positivos de primeiro dia (underpricing).

O período dos dados coletados iniciou-se em 24.05.2004, data do IPO da primeira empresa da amostra, Natura Cosméticos. O último IPO a ingressar na amostra foi o da empresa Ourofino, cuja oferta realizou-se em 17.10.2014. Cada ação de empresa apresenta pelo menos dois anos completos de negociação e de dados, razão pela qual não foram incluídos IPOs realizados a partir de 2015. Alguns estudos cobrem o período de 2004-2008 com amostra menor (Tavares e Minardi, 2010; Ferrari e Minardi, 2010). Outros artigos, como Minardi et al (2013) incluem os BDRs. Retiram-se da amostra as ações de bancos devido às suas estruturas de capital de difícil mensuração, se comparadas às demais empresas da amostra. Destaca-se que nenhum dos bancos que abriu capital no Brasil, no período de estudo, foi previamente investido por fundos PE.

Foi excluída também a ação da empresa Raia, em virtude de sua fusão com a Drogasil, menos de dois anos após o IPO, não atingindo a periodicidade mínima de negociação para ingressar na amostra final. Neste artigo são incluídos os Brazilian Depositary Receipt (BDR), excluídas as ações de BM\&F, Bovespa e BM\&FBovespa, devido à fusão das duas primeiras gerando a terceira ( Silva e Famá, 2011) e excluída também a ação da empresa Raia, em virtude de sua fusão com a Drogasil, menos de dois anos após o IPO, não atingindo a periodicidade mínima de negociação para ingressar na amostra final. Os dados foram submetidos à estatística descritiva.

\subsection{Metodologia Wealth Relative Buy-and-Hold e o ajuste ao risco individual do ativo}

Ritter (1991), Brav e Gompers (1997) e Cao e Lerner (2009) medem o retorno das ações das empresas investidas por fundos PE em razão de um índice de referência, através do critério Wealth Relative, baseado na criação de riqueza ao acionista, ou seja, a razão entre o retorno buy-andhold da ação da empresa desde o IPO e o retorno buy-and-hold de um portfólio representado pelo benchmark do mercado, no mesmo período. Wealth Relative pode ser definida como riqueza relativa criada ao acionista, decorrente do retorno da ação em face do retorno de um índice referencial. Buy-and-hold é uma estratégia muito comum entre investidores no mercado de ações e consiste em "comprar e segurar" 
determinado ativo, com vistas a obter melhores retornos de longo prazo (long-run), ignorando assim volatilidades de curto prazo.

A fórmula do Wealth Relative Buy-and-Hold (WR) é assim descrita:

$$
W R t=\frac{\sum(1+R i, t)}{\sum(1+R \text { bench } i, t)}
$$

onde

$\mathrm{R} i, t=$ retorno buy-and-hold do ativo $i$ no período $T$, sendo $T$ os diferentes períodos anuais de 1 até 5 anos após o IPO e,

$\mathrm{R}$ bench $i, t=$ retorno do portfólio do mercado (benchmark) no mesmo período de 1 até 5 anos após o IPO do ativo $i$.

De acordo com Ritter (1991), um Wealth Relative maior do que 1,00 pode ser interpretado como um melhor desempenho da ação pós-IPO face ao benchmark e menor que 1,00 pode-se concluir que o IPO teve performance inferior à carteira de referência.

Os retornos anuais das ações das empresas e do benchmark do mercado são assim calculados:

$\mathrm{R} \mathrm{i}, \mathrm{t}=$ retorno buy-and-hold da empresa i no período $t$, sendo $t$ os diferentes períodos anuais de 1 a 5 anos após o IPO:

$$
R i, t=\frac{P i, t}{P i, t-1}-1
$$

$\mathrm{R}$ bench $\mathrm{i}, \mathrm{t}=$ retorno do benchmark (Ibovespa) no mesmo período:

$$
R \text { bench } i, t=\frac{P \text { bench } i, t}{P \text { bench } i, t-1}-1
$$

Brav e Gompers (1997) e Gompers e Lerner (2003) propõem ponderar os retornos pelo valor de mercado das ações. Ritter (1991) calcula o retorno da ação pós-IPO sem ajustá-lo ao risco, representado pelo coeficiente beta. Destaca que os betas das empresas pós-IPO são, na média, maiores que 1,00 e declinam em períodos futuros após a oferta pública. A contribuição deste artigo ao tema consiste em ajustar o WR original ao risco individual da ação, apurado pelo seu beta $(\beta)$, de modo a ponderar os retornos relativos, obtidos nos anos posteriores ao IPO, ao risco do investidor buy-and-hold no mercado brasileiro. Desta forma, inova-se em relação a trabalhos anteriores sobre o mesmo tema ao propor o ajuste da fórmula original do WR, utilizada em Ritter (1991), Brav e Gompers (1997) e Cao e Lerner (2009), ao risco individual da ação conforme a equação (4), calculando o Wealth Relative Risk Adjusted 
(WRRA). Esta equação (4) representa a contribuição principal deste artigo e incorpora à equação (1) o risco idiossincrático do ativo, representado pelo seu coeficiente beta.

$$
W R R A t=\frac{\sum(1+R i, t)}{\sum(1+R \text { bench } i, t)} \times \frac{1}{\beta i, t}
$$

Ou, escrito de forma simplificada:

$$
\text { WRRA } t=\frac{W R t}{\beta i, t}
$$

Onde $\beta i$ representa o beta do ativo, calculado pela covariância entre os retornos mensais do ativo $i$ e os retornos mensais do benchmark, divididos pela variância dos retornos mensais do benchmark, todos calculados nos períodos $t$ de 1 a 5 anos pós-IPO.

$$
\beta i, t=\frac{\operatorname{Cov}(R i, t ; \text { Rbench }, t)}{\operatorname{Var}(\text { Rbench }, t)}
$$

Apresentam-se assim três possibilidades: 1 . Se o beta do ativo for exatamente igual ao beta da carteira representada pelo Índice Bovespa, ou seja, 1,00, o WRRA em $t$ será exatamente igual ao WR no mesmo período $t$;; 2 . Em casos de ativo com beta menor que 1,00 , ou seja, com menos risco que a carteira de mercado, o WRRA em $t$ será maior do que o WR em $t$ e; 3. Caso o beta seja $>1,00$, ou seja, o ativo apresenta mais risco se comparado ao benchmark, em $t$ o WRRA será menor que o WR.

As cotações das ações, fornecidas pelo portal Bloomberg, referem-se a períodos anuais $t$ de 1 a 5 anos após a oferta pública e foram ajustadas a proventos, para capturar o efeito dos dividendos, juros sobre capitais próprios, bonificações, splits e inplits.

Os dados dos coeficientes beta também são fornecidas pelo portal Bloomberg, calculados a partir dos retornos mensais do ativo em função dos retornos mensais do Índice Bovespa, a partir da data do IPO. Os diferentes betas dos períodos $t$, calculados sobre retornos mensais, utilizam dados menos voláteis do que aqueles calculados sobre retornos semanais ou diários. Obtém-se então um beta na mesma periodicidade dos retornos relativos estudados, de forma a mensurar o retorno relativo do período em face do risco incorrido no mesmo período.

Os resultados obtidos com a análise dos retornos das ações de empresas PE e NPE encontram-se no capítulo 4. Opta-se por mantê-los em resultado puro e não porcentagem, ou seja, resultados acima de 1,000 significam um desempenho superior ao Ibovespa no período e resultados abaixo de 1,000 traduzem um retorno inferior ao benchmark, sejam os 
retornos simples sem ponderação ao risco ou calculados em face do risco individual do ativo, incorporado à formula pelo coeficiente beta do período.

São usadas as seguintes variáveis na construção dos modelos:

Wealth Relative (WR): riqueza relativa criada ao acionista ou o retorno relativo da ação da empresa em face do benchmark, sem a ponderação pelo risco individual, baseada em Brav e Gompers (1997) e Cao e Lerner (2009) e obtida a partir da fórmula descrita em (1). Foram calculados os retornos $W R$ de 1 a 5 anos, após a data do IPO da empresa (WRI a WR5). As cotações das ações e do benchmark Ibovespa, ambas ajustadas a proventos, são fornecidas pela base de dados Bloomberg.

Wealth Relative Risk Adjusted (WRRA): riqueza relativa criada ao acionista ou o retorno relativo da ação da empresa em face do benchmark, baseada em Brav e Gompers (1997) e Cao e Lerner (2009), e adaptada ao risco individual do ativo, calculada a partir da fórmula descrita em (4) e (4a). Foram obtidos os retornos WRRA de 1 a 5 anos, após a data do IPO da empresa (WRRAl a WRRA5). As cotações dos coeficientes beta utilizados são calculadas e fornecidas pela base de dados Bloomberg.

Private Equity (PE): variável dummy indicando a presença de um fundo PE na composição acionária da empresa, por ocasião do IPO, sendo 1 para a presença do fundo e 0 na ausência.

Segmento de Mercado (SM): variável dummy para o segmento de listagem da BM\&FBovespa onde a ação da empresa é negociada, de acordo com as regras de governança corporativa. Assume valores de 1 para as empresas negociadas no Novo Mercado (NM), nível máximo de governança corporativa e 0 para os demais segmentos, Níveis 1 e 2, BDRs e segmento tradicional. Os dados são fornecidos pela BM\&FBovespa.

Logaritmo natural do Volume da Oferta Primária (1_VOP): variável para o volume total de recursos captado pela empresa em oferta primária, por ocasião do IPO. O volume captado nestas condições representa novas ações emitidas a novos acionistas e o montante é direcionado ao caixa da empresa e não aos acionistas originais. Para Kaplan e Schoar (2005) empresas com acesso a uma quantidade maior de recursos no IPO podem realizar melhores investimentos e assim, proporcionar melhores retornos aos acionistas. Utilizada por Jain e Kini (1995), Tavares e Minardi (2010), Ferrari e Minardi (2010). O volume da oferta primária é fornecido diretamente pela BM\&FBovespa e o logaritmo natural é calculado sobre os dados. 
Debt-to-Equity (DE): variável para a divisão do valor da dívida total (curto + longo prazo) da empresa pelo valor do patrimônio líquido, nos diferentes períodos $T$. Para Welch (2004), os retornos das ações são mais importantes para explicar o debt-to-equity do que outros fatores. Os dados são fornecidos pela Bloomberg.

Underpricing (UN): variável de retorno de primeiro dia, ou seja, diferença entre o valor da precificação da ação no momento do IPO e a cotação de fechamento no primeiro dia de negociação do ativo no mercado secundário. A fórmula para cálculo do underpricing, consoante Boulton et al (2011), é assim definida:

$$
U N=\frac{\text { Preço de fechamento da ação no fim do 1ำ dia }}{\text { Preço da ação no lançamento }}-1
$$

Market-to-Book (MB): variável da razão entre o valor de mercado da ação (market) pelo valor patrimonial na data do IPO e nos períodos $T$ subsequentes, de 1 a 5 anos (book). Para Frank e Goyal (2009) é uma variável associada às oportunidades de crescimento da empresa e um alto market-to-book pode decorrer de uma precificação errada da ação. É utilizada em diversos artigos sobre o tema, como Brav e Gompers (1997), Tavares e Minardi (2010) e Minardi et al (2013). Os dados são fornecidos pela Bloomberg e Economática.

Número total de investidores (NI): representa o número de novos investidores, pessoas físicas e jurídicas, na oferta pública inicial de ações. Os dados são fornecidos pela BM\&FBovespa.

Os modelos de regressão testados, com dados em cross-section, são os seguintes.

De início, testa-se dois modelos simples, em todos os períodos, onde os WR e WRRA são observados em regressões simples contra a variável explicativa PE, conforme (7) e (8):

$$
\begin{gathered}
W R=\alpha+\beta 1 P E+\varepsilon \\
W R R A=\alpha+\beta 1 P E+\varepsilon
\end{gathered}
$$

As equações (7) e (8) testam $\mathrm{H} 3$ e H4, ou seja, se a presença de um fundo PE é estatisticamente significante para explicar os retornos relativos da ação pós-IPO, ponderados ou não pelo risco individual, em regressão simples.

As equações (9) e (10) testam H3 e H4 por regressão múltipla, ou seja, se, em conjunto com as demais variáveis independentes, a presença de um fundo PE mantem-se ou não com significância estatística para que explicar 
os retornos relativos da ação pós-IPO, ponderados ou não pelo risco individual.

$$
\begin{array}{r}
W R=\alpha+\beta 1 P E+\beta 2 S M+\beta 3 l_{-} V O P+\beta 4 D E+\beta 5 U N+ \\
\beta 6 M B+\beta 7 N I+\varepsilon \\
W R R A=\alpha+\beta 1 P E+\beta 2 S M+\beta 3 l_{-} V O P+\beta 4 D E+\beta 5 U N+\beta 6 M B+ \\
\beta 7 N I+\varepsilon
\end{array}
$$

A tabela 1 apresenta as variáveis testadas no estudo, o método de teste

\begin{tabular}{|c|c|c|}
\hline Hipóteses & Método de teste & $\begin{array}{c}\text { Resultados esperados para se } \\
\text { confirmar a hipótese }\end{array}$ \\
\hline H1: WR PE > WR NPE & $\begin{array}{l}\text { Estatística descritiva } \\
\text { e teste } t \text { de média }\end{array}$ & $\begin{array}{l}\text {-média WRPE > média WRNPE } \\
\text { para todos os } 5 \text { anos pós-IPO } \\
\text { testados, com nível de significância } \\
\text { de } 1 \%\end{array}$ \\
\hline H2: WRRA PE > WRRA NPE & $\begin{array}{l}\text { Estatística descritiva } \\
\text { e teste } t \text { de média }\end{array}$ & $\begin{array}{l}\text {-média WRRA PE > média WRRA } \\
\text { NPE para todos os } 5 \text { anos pós-IPO } \\
\text { testados, com nível de significância } \\
\text { de } 1 \%\end{array}$ \\
\hline $\begin{array}{l}\text { H3: A presença da variável PE é } \\
\text { estatisticamente significante para } \\
\text { explicar os WR em todos os } 5 \text { anos } \\
\text { pós-IPO. }\end{array}$ & $\begin{array}{l}\text { Equação (7), } \\
\text { regressão simples e } \\
\text { equação (9), } \\
\text { regressão múltipla }\end{array}$ & $\begin{array}{l}\text {-coeficiente beta positivo em PE e } \\
\text { níveis de significância estatística de } \\
1 \%(* * *), 5 \%(* *) \text { e } 10 \%(*) \text {, em } \\
\text { todos os } 5 \text { anos pós-IPO. }\end{array}$ \\
\hline $\begin{array}{l}\text { H4: A presença da variável PE é } \\
\text { estatisticamente significante para } \\
\text { explicar os WRRA em todos os } 5 \\
\text { anos pós-IPO. }\end{array}$ & $\begin{array}{l}\text { Equação (8), } \\
\text { regressão simples e } \\
\text { equação (10), } \\
\text { regressão múltipla }\end{array}$ & $\begin{array}{l}\text { coeficiente beta positivo em PE e } \\
\text { níveis de significância estatística de } \\
1 \%(* *), 5 \%(* *) \text { e } 10 \%(*) \text {, em } \\
\text { todos os } 5 \text { anos pós-IPO. }\end{array}$ \\
\hline
\end{tabular}
e os resultados esperados.

Tabela 1

Hipóteses testadas, métodos de testes utilizados e resultados esperados para se aceitar a hipótese nula

Fonte: elaborado pelos autores.

As regressões com dados em cross-section para os retornos relativos de 1 a 5 anos (WR e WRRA) são testadas pelo método dos Mínimos Quadrados Ordinários (MQO ou OLS), com erros padrão robustos, de acordo com o teste de White. 


\section{Resultados}

As tabelas 2 e 3 fornecem, respectivamente os números dos IPOs segmentados por ano, entre 2004 e 2014 e a matriz de correlação entre as variáveis utilizadas em seu primeiro ano pós-IPO.

Tabela 2

IPOs utilizados no estudo, segmentados por ano, 2004-2014

\begin{tabular}{cccccccccccc}
\hline & 2004 & 2005 & 2006 & 2007 & 2008 & 2009 & 2010 & 2011 & 2012 & 2013 & 2014 \\
\hline Empresas PE & 5 & 4 & 13 & 19 & 2 & 4 & 5 & 10 & 1 & 4 & 0 \\
Empresas NPE & 2 & 4 & 13 & 33 & 2 & 1 & 5 & 1 & 1 & 6 & 1 \\
\hline
\end{tabular}

Fonte: BM\&FBovespa. Elaborado pelos autores.

Tabela 3

Matriz de correlação entre as variáveis de $1^{\circ}$ ano pós-IPO

\begin{tabular}{|c|c|c|c|c|c|c|c|c|c|}
\hline & WRRA1 & WR1 & PE & SM & UN & MB & $\mathrm{DE}$ & NI & 1_VOP \\
\hline WRRA1 & 1,000 & & & & & & & & \\
\hline WR1 & 0,2368 & 1,000 & & & & & & & \\
\hline PE & $-0,0378$ & 0,2557 & 1,000 & & & & & & \\
\hline SM & $-0,0861$ & $-0,1425$ & $-0,2781$ & 1,000 & & & & & \\
\hline UN & $-0,0989$ & 0,4950 & 0,0843 & $-0,0878$ & 1,000 & & & & \\
\hline MB & $-0,0065$ & 0,2419 & 0,1291 & $-0,3356$ & 0,4230 & 1,000 & & & \\
\hline $\mathrm{DE}$ & 0,0197 & $-0,1393$ & $-0,0361$ & 0,1069 & $-0,1058$ & $-0,0361$ & 1,000 & & \\
\hline NI & $-0,2781$ & $-0,1742$ & $-0,0808$ & $-0,0104$ & 0,2279 & 0,1843 & 0,1717 & 1,000 & \\
\hline 1_VOP & $-0,700$ & $-0,0629$ & $-0,2341$ & 0,1458 & $-0,0149$ & $-0,0617$ & 0,2733 & 0,1273 & 1,000 \\
\hline
\end{tabular}

Fonte: Bloomberg e Economática. Elaborado pelos autores.

Nota: $5 \%$ valor crítico $($ bicaudal $)=0,1832$ para $\mathrm{n}=115$, valores ausentes ignorados.

As tabelas 4 a 8 fornecem os resultados das estatísticas descritivas das variáveis utilizadas para os diversos períodos $t$, medidos em anos, após o IPO. As variáveis PE e SM não foram avaliadas pois, como dummies, assumem apenas valores 0 e 1 . As variáveis 1_VOP, UN e NI estão apenas na tabela 4, pois são constantes ao longo dos cinco anos analisados. Observa-se uma maior volatilidade durante os cinco anos, representada pelo desvio-padrão, em WRRA se comparada a WR. Na média, o WRRA também superou o WR em todos os cinco anos e na mediana, superou em quatro. Tais números apontam que, na média, o beta das novas ações, mensurado após o IPO, é inferior a 1,00 (consoante equação 4a). 
Tabela 4

Estatísticas Descritivas para o $1^{\circ}$ ano pós-IPO, usando as observações 1 - 136

\begin{tabular}{ccccccccccccc}
\hline Variável & Média & Mediana & Mínimo & Máximo & D. Padrão & C.V. & Env. & Curtose Ex. & Perc. 5\% & Perc. 95\% & Interv. IQ & O.A. \\
\hline WRRA1 & 1,78 & 1,18 & $-26,49$ & 22,17 & 3,82 & 2,15 & $-1,03$ & 28,52 & 0,12 & 6,73 & 1,72 & 0 \\
WR1 & 1,04 & 0,96 & 0,03 & 4,00 & 0,55 & 0,53 & 1,43 & 5,15 & 0,36 & 1,82 & 0,79 & 0 \\
UN & 0,04 & 0,01 & $-0,20$ & 1,05 & 0,13 & 2,79 & 3,95 & 28,97 & $-0,09$ & 0,20 & 0,12 & 0 \\
MB & 5,51 & 2,63 & 0,46 & 133,65 & 13,19 & 2,39 & 7,56 & 66,52 & 0,94 & 23,89 & 2,19 & 2 \\
DE & 1,84 & 0,63 & $-0,98$ & 27,12 & 4,03 & 2,19 & 3,96 & 17,35 & 0,00 & 10,64 & 1,27 & 4 \\
NI & 8698 & 5448 & 8,00 & 114335 & 12234 & 1,41 & 5,32 & 40,27 & 175,90 & 25581 & 10453 & 0 \\
1_VOP & 5,95 & 6,03 & 2,77 & 8,81 & 0,86 & 0,14 & $-0,52$ & 2,49 & 4,62 & 7,09 & 0,90 & 12 \\
\hline
\end{tabular}

Fonte: Bloomberg e Economática. Elaborado pelos autores.

Nota: Valores ausentes ignorados.

Tabela 5

Estatísticas Descritivas para o $2^{\circ}$ ano pós-IPO, usando as observações 1 - 136

\begin{tabular}{|c|c|c|c|c|c|c|c|c|c|c|c|c|}
\hline Variável & Média & Mediana & Mínimo & Máximo & D. Padrão & C.V. & Env. & Curtose Ex. & Perc. 5\% & Perc. 95\% & Interv. IQ & O.A. \\
\hline WRRA2 & 1,42 & 0,86 & 0,04 & 14,74 & 1,77 & 1,25 & 4,20 & 25,26 & 0,14 & 3,82 & 1,56 & 0,00 \\
\hline WR2 & 1,04 & 0,82 & 0,07 & 10,63 & 1,06 & 1,02 & 5,59 & 46,91 & 0,18 & 2,40 & 0,93 & 0,00 \\
\hline MB & 4,37 & 2,21 & 0,20 & 62,02 & 7,59 & 1,74 & 4,65 & 27,43 & 0,40 & 18,86 & 3,31 & 3,00 \\
\hline $\mathrm{DE}$ & 0,39 & 0,30 & $-3,65$ & 3,46 & 0,64 & 1,62 & $-0,55$ & 14,64 & 0,00 & 1,47 & 0,56 & 2,00 \\
\hline
\end{tabular}

Fonte: Bloomberg e Economática. Elaborado pelos autores.

Nota: Valores ausentes ignorados. 
Tabela 6

Estatísticas Descritivas para o $3^{\circ}$ ano pós-IPO, usando as observações 1 - 132

\begin{tabular}{|c|c|c|c|c|c|c|c|c|c|c|c|c|}
\hline Variável & Média & Mediana & Mínimo & Máximo & D. Padrão & C.V. & Env. & Curtose Ex. & Perc. 5\% & Perc. $95 \%$ & Interv. IQ & O.A. \\
\hline WRRA3 & 1,49 & 0,84 & 0,05 & 15,04 & 2,05 & 1,38 & 3,71 & 17,15 & 0,15 & 5,18 & 1,20 & 0,00 \\
\hline WR3 & 1,09 & 0,77 & 0,07 & 10,16 & 1,13 & 1,04 & 4,48 & 30,81 & 0,17 & 2,70 & 0,94 & 0,00 \\
\hline MB & 5,72 & 1,81 & 0,36 & 250,66 & 22,80 & 3,99 & 9,88 & 102,78 & 0,49 & 20,44 & 1,94 & 4,00 \\
\hline $\mathrm{DE}$ & 0,65 & 0,37 & $-1,85$ & 11,12 & 1,19 & 1,82 & 5,49 & 44,28 & 0,00 & 2,62 & 0,77 & 0,00 \\
\hline
\end{tabular}

Fonte: Bloomberg e Economática. Elaborado pelos autores.

Nota: Valores ausentes ignorados.

Tabela 7

Estatísticas Descritivas para o $4^{\circ}$ ano pós-IPO, usando as observações $1-116$

\begin{tabular}{ccccccccccccc}
\hline \multicolumn{1}{c}{ Variável } & Média & Mediana & Mínimo & Máximo & D. Padrão & C.V. & Env. & Curtose Ex. & Perc. 5\% & Perc. 95\% & Interv. IQ & O.A. \\
\hline WRRA4 & 1,37 & 0,79 & 0,01 & 17,31 & 2,02 & 1,48 & 4,95 & 32,78 & 0,11 & 5,23 & 1,06 & 0,00 \\
WR4 & 1,12 & 0,80 & 0,01 & 11,56 & 1,36 & 1,21 & 4,74 & 30,37 & 0,10 & 2,89 & 0,98 & 0,00 \\
MB & 5,55 & 1,93 & 0,09 & 200,52 & 19,53 & 3,52 & 9,03 & 86,70 & 0,56 & 18,68 & 2,35 & 3,00 \\
DE & 1,29 & 0,51 & $-5,94$ & 65,30 & 6,15 & 4,75 & 9,83 & 99,74 & 0,00 & 2,89 & 0,76 & 0,00 \\
\hline
\end{tabular}

Fonte: Bloomberg e Economática. Elaborado pelos autores.

Nota: Valores ausentes ignorados.

Tabela 8

Estatísticas Descritivas para o $5^{\circ}$ ano pós-IPO, usando as observações $1-108$

\begin{tabular}{|c|c|c|c|c|c|c|c|c|c|c|c|c|}
\hline Variável & Média & Mediana & Mínimo & Máximo & D. Padrão & C.V. & Env. & Curtose Ex. & Perc. 5\% & Perc. 95\% & Interv. IQ & O.A. \\
\hline WRRA5 & 1,45 & 0,89 & 0,00 & 18,47 & 2,11 & 1,46 & 5,34 & 37,88 & 0,05 & 4,62 & 1,35 & 0,00 \\
\hline WR5 & 1,20 & 0,88 & 0,00 & 11,19 & 1,39 & 1,16 & 4,02 & 23,51 & 0,07 & 3,77 & 1,03 & 0,00 \\
\hline MB & 2,75 & 1,51 & 0,07 & 23,55 & 3,76 & 1,37 & 3,48 & 13,86 & 0,42 & 9,28 & 1,95 & 3,00 \\
\hline $\mathrm{DE}$ & 2,38 & 0,63 & $-1,06$ & 164,90 & 15,81 & 6,65 & 10,19 & 102,24 & 0,00 & 3,33 & 0,78 & 0,00 \\
\hline
\end{tabular}

DE $\quad 2,38$

Nota: Valores ausentes ignorados. 
$\mathrm{Na}$ sequência, apresentam-se as análises dos resultados, a começar pelo primeiro momento após a estreia da nova ação no mercado secundário, a ocorrência ou não de underpricing de primeiro dia, seguidos pelas análises das performances anuais, ponderadas ou não pelo risco individual do ativo.

\subsection{Underpricing das ações no primeiro dia de negociação}

Na média, as ações de empresas brasileiras que abriram capital após 2004, apresentaram um underpricing médio de 4,48\%, resultado próximo ao estudo de Minardi et al (2015). As empresas investidas por fundos PE possuem, na média, underpricing superior às NPE, 5,35\% x 3,64\%. A diferença, em princípio substancial, deve-se à presença de um outlier, a empresa Tarpon, com underpricing de 105\%, no grupo das empresas PE. Optou-se por excluir este outlier pois seu atípico underpricing encontra-se mais de 8 desvios-padrão da média de todas as empresas da amostra $(4,48 \%)$. Retirando-o da amostra, tem-se um resultado mais próximo entre os dois grupos $(3,84 \% \times 3,64 \%)$. Todavia, o teste $t$ de diferença entre as médias dos dois grupos não é estatisticamente significante a $1 \%$, conforme observado na tabela 9.

\section{Tabela 9}

Médias UN, PE x NPE, com/sem outlier. Teste T de 2 médias; H0: diferença de médias=0; H1: média $\mathrm{PE}>$ média NPE

\begin{tabular}{ccc}
\hline & $\mathrm{UN}$ (com outlier) & $\mathrm{UN}$ (sem outlier) \\
\hline $\mathrm{PE}$ & $5,35 \%$ & $3,84 \%$ \\
$\mathrm{NPE}$ & $3,64 \%$ & $3,64 \%$ \\
teste $t$ & 0,788877 & 0,12675 \\
\hline
\end{tabular}

Fonte: Bloomberg. Elaborado pelos autores

Nota: Teste T de 2 médias; H0: diferença de médias=0; H1: média1 > média2; amostra média PEamosta média NPE. $* * *$ sig.est. a $1 \%$; **sig.est a $5 \%$; *sig.est a $10 \%$.

Devido ao maior underpricing no grupo das empresas investidas por fundos PE, os resultados contradizem os trabalhos de Barry, Muscarella, Peavey e Vetsuypens (1990), Brav e Gompers (1997), Chemmanur e Loutskina (2005) e Ferrari e Minardi (2010). A contrario sensu, o estudo de Lee e Wahal (2002), assevera que, em períodos de euforia de mercado, a "publicidade favorável" associada à uma empresa investida por um fundo $\mathrm{PE}$, leva a um underpricing maior, pois investidores tornam-se mais ávidos a adquirir a ação, por ocasião da abertura das negociações em mercado 
secundário. Cerca de 56\% das empresas da amostra realizaram suas ofertas públicas no biênio 2006-7, período de intenso bull market no mercado brasileiro de ações.

\subsection{WR e WRRA de um a cinco anos após o IPO}

Calculam-se os retornos relativos anuais nos períodos de 1 até 5 anos (WR1 a WR5) consoante equação (1) e os retornos relativos ponderados pelo seu risco em igual período (WRRA1 a WRRA5), consoante equações (4) e (4a). A figura 1 apresenta a evolução dos retornos simples (WR) e ponderados pelo risco (WRRA) entre todas as empresas que abriram capital após 2004. Nota-se que, na média da amostra total, sem a segmentação PE-NPE, WR e WRRA ultrapassam o Índice Bovespa ao longo dos cinco anos $(>1,000)$. Portanto, os retornos de uma carteira composta por ações de empresas adquiridas por ocasião da precificação do IPO, ponderados ou não pelo risco individual dos ativos, tende, na média, a superar o benchmark em uma estratégia buy-and-hold com até cinco anos de horizonte temporal. Como contraponto, Ritter (1991) analisa 1.526 IPOs realizados nos Estados Unidos, no período 1975-84 e conclui que, três anos após a oferta pública, os retornos são, em média, negativos em $17 \%$.

\section{Figura 1}

WR e WRRA (média do total da amostra-1 a 5 anos)

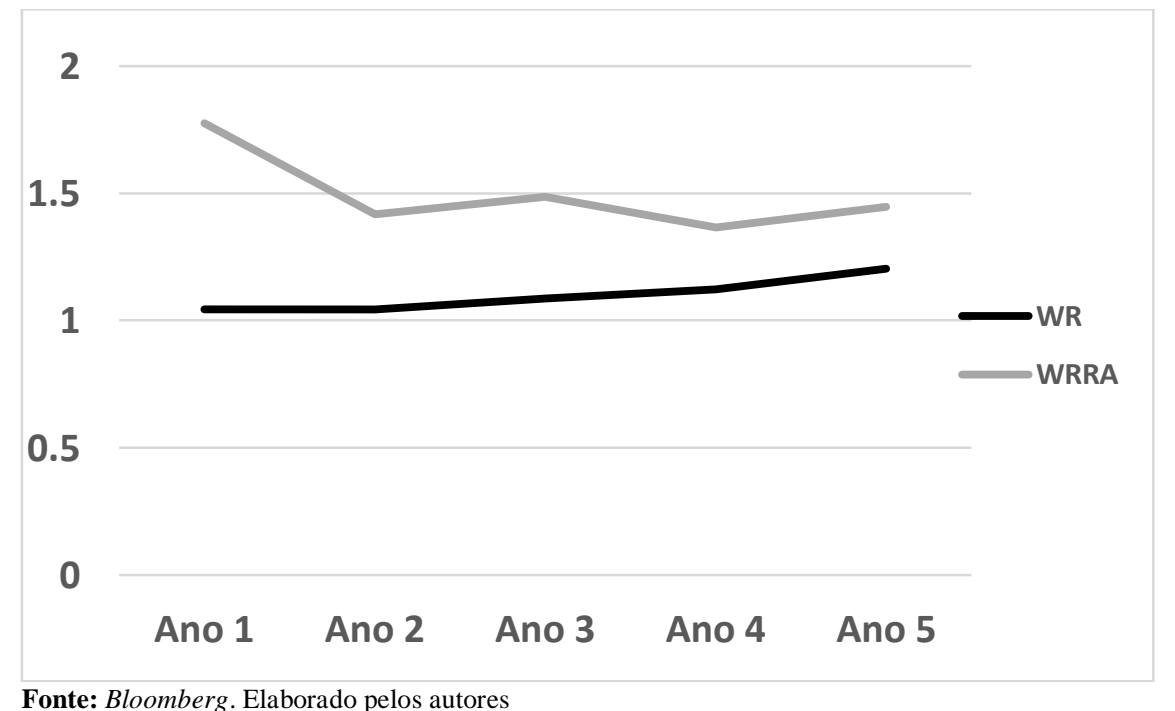

Fonte: Bloomberg. Elaborado pelos autores 
Os resultados apontam que os WR das empresas investidas por fundos PE foram, na média, superiores às não-investidas, em todos os cinco anos estudados, similares a Jain e Kini (1995), Brav e Gompers (1997), Cao e Lerner (2009) e Minardi et al (2013). No entanto, os testes $t$ revelam significância estatística a 1\%, apenas para as diferenças de média em WR1 e WR2. Quando ponderados os retornos pelo risco, em WRRA, a vantagem das empresas investidas por fundos PE revela-se no $2^{\circ}, 3^{\circ}, 4^{\circ}$ e $5^{\circ}$ ano pósIPO. Todavia, o teste $t$ de diferenças de média entre os dois grupos não é estatisticamente significante a $1 \%$ em nenhum ano do WRRA. As diferenças das médias no WR e no WRRA entre PE e NPE se mantém com o passar dos anos, contudo, sem significância estatística. Chemmanur e Loutskina (2005), Levis (2011) e Minardi et al (2013) apontam que a vantagem das empresas PE perdura por cerca de dois a três anos após o IPO. A síntese dos resultados encontra-se na tabela 9 e nas figuras 2 e 3.

Tabela 10

Média WR e WRRA, total da amostra (PE + NPE) e teste $t$ de diferença de duas médias

\begin{tabular}{|c|c|c|c|c|c|c|c|c|c|c|}
\hline & WR1 & WRRA1 & WR2 & WRRA2 & WR3 & WRRA3 & WR4 & WRRA4 & WR5 & WRRA5 \\
\hline médiaPE & 1,1746 & 1,6228 & 1,2570 & 1,6718 & 1,2635 & 1,7322 & 1,3206 & 1,6439 & 1,3235 & 1,6151 \\
\hline médiaNPE & 0,9180 & 1,9188 & 0,8367 & 1,1708 & 0,9120 & 1,2485 & 0,9186 & 1,0778 & 1,0797 & 1,2754 \\
\hline Teste $t$ & $2,7948^{* * * *}$ & $-0,4422$ & 2,3459 *** & $1,6635^{*}$ & $1,8076^{* *}$ & 1,3577 & $1,62314^{*}$ & 1,53545 & 0,91724 & 0,84328 \\
\hline PE $>1,00$ & 59,70 & 64,18 & 47,76 & 50,74 & 46,15 & 52,30 & 38,98 & 40,67 & 41,81 & 47,27 \\
\hline $\mathrm{NPE}>1,00$ & 34,78 & 49,27 & 30,88 & 33,33 & 28,35 & 32,83 & 40,35 & 36,84 & 47,17 & 47,17 \\
\hline Teste $t$ & 0,7193 & $-0,6399$ & 1,1115 & 0,4038 & 0,7424 & 0,0691 & 2,113 ** & $1,6134 *$ & 1,3968 & 0,9229 \\
\hline $\begin{array}{c}\text { Empresas } \\
>1,00 \\
\% \mathrm{PE}\end{array}$ & 62,50 & 55,84 & 60,37 & 59,65 & 61,22 & 60,71 & 50 & 53,33 & 47,91 & 50,98 \\
\hline $\begin{array}{c}\text { Empresas } \\
>1,00 \\
\% \mathrm{NPE}\end{array}$ & 37,50 & 44,16 & 39,63 & 40,35 & 38,77 & 39,29 & 50 & 46,67 & 52,09 & 49,02 \\
\hline
\end{tabular}

Fonte: Bloomberg. Elaborado pelos autores.

Nota: Teste t de 2 médias; H0: diferença de médias=0; H1: média1 > média2; amostra média PE-

amosta média NPE. *** sig.est. a $1 \%$; **sig.est a $5 \%$; *sig.est a $10 \%$. 
Figura 2

WR1 a WR5: (médias-PE X NPE)

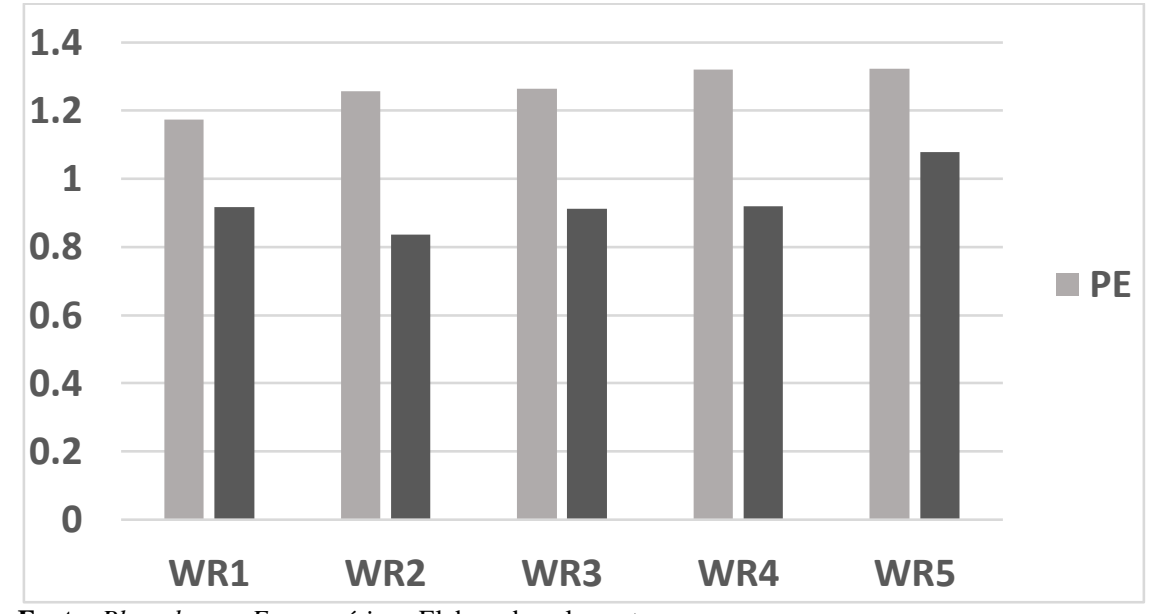

Fonte: Bloomberg e Economática . Elaborado pelos autores.

Figura 3

WRRA1 a WRRA5: (médias -PE X NPE)

\section{5}

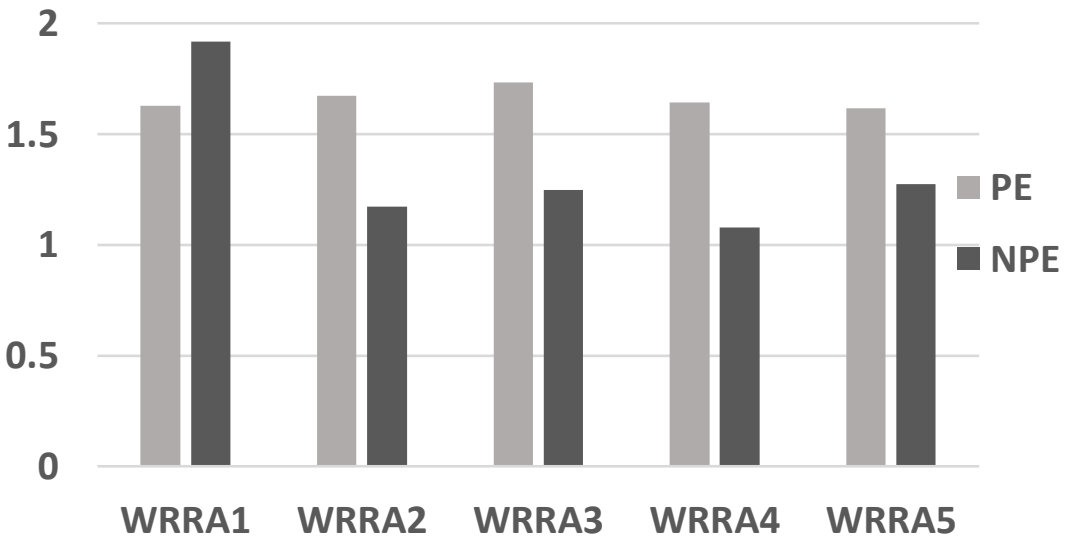

Fonte: Bloomberg e Economática. Elaborado pelos autores. 
Tabela 11

Teste não-paramétrico da diferença: teste dos sinais, número de casos WRPE > WRNPE e WRRAPE $>$ WRRANPE

\begin{tabular}{lcc}
\hline & WRPE $>$ WRNPE & WRRAPE > WRRANPE \\
\hline Ano 1 & $59,70 \%$ & $55,22 \%$ \\
Ano 2 & $64,18 \%$ & $61,19 \%$ \\
Ano 3 & $53,85 \%$ & $58,46 \%$ \\
Ano 4 & $56,14 \%$ & $52,63 \%$ \\
Ano 5 & $50,94 \%$ & $56,60 \%$ \\
\hline
\end{tabular}

Fonte: Bloomberg e Economática. Elaborado pelos autores

Os resultados levantados apontam os WR1 a WR5 superiores, na média, em empresas investidas por fundos PE. No entanto, corrobora-se H1 apenas em WR1 e WR2 (significância estatística a 1\%, tabela 9). Temse que $59,7 \%$ das empresas investidas por fundos PE obtiveram WR1 superiores a 1,000 contra 34,78 das NPE, resultado, portanto, superior ao Índice Bovespa. Esta superioridade das primeiras manteve-se até WR3. Considerando a amostra total, $62,5 \%$ das empresas com WR1 superior ao Ibovespa $(>1,000)$ pertencem ao grupo de investidas por fundos PE, contra $37,5 \%$ as quais pertencem ao grupo das NPE, vantagem numérica se mantém até WR3. Uma possível explicação pode ser a valorização pelo mercado da boa herança administrativa das empresas investidas por fundos PE, antes da oferta pública, levantada em artigos de Brav e Gompers (1997), Cao e Lerner (2009), Tavares e Minardi (2010), Levis (2011) e Minardi et al (2013). As diferenças das médias no WR entre PE e NPE se mantém com o passar dos anos, mas só apresentam significância estatística a $1 \%$ em WR1 e WR2.

Resultado semelhante obtém-se no WRRA1, onde $64,18 \%$ das empresas investidas por fundos PE apresentam valores superiores a 1,000, contra 49,27\% das NPE. Considerando a amostra total, 62,5\% das empresas com WR1 superior ao Ibovespa $(>1,000)$ pertencem ao grupo de investidas por fundos $\mathrm{PE}$, contra $37,5 \%$ as quais pertencem ao grupo das NPE. Conclusão semelhante encontra-se na análise do WRRA1, pois $55,84 \%$ de empresas investidas por fundos PE apresentam resultados acima do benchmark, contra 44,16\% das NPE. Nos demais anos, entre as empresas com WRRA acima de 1,00 observa-se porcentagem maior das investidas por fundos PE e entre as empresas com WR acima de 1,00, a maior porcentagem das NPE só aparece a partir do $5^{\circ}$ ano após a oferta pública. Tais números estão em sintonia com os encontrados por Brav e 
Gompers (1997), Levis (2011) e Minardi et al (2013), cujos estudos sugerem maiores retornos às ações de empresas investidas por fundos PE, nos primeiros anos após a oferta pública. Após alguns anos, as ações das empresas investidas por fundos $\mathrm{PE}$ já não oferecem um desempenho superior às NPE, sugerindo o reconhecimento do mercado apenas nos primeiros anos após o IPO.

\subsection{Debt-to-Equity e Market-to-Book}

Na média, empresas investidas por fundos PE são menos endividadas e possuem um market-to-book menor, se comparadas às NPE, no primeiro ano pós-IPO. Minardi et al (2013) encontram maior endividamento e um menor MB entre as empresas NPE, no período 2004-2008. Os resultados apontam menor alavancagem nas empresas PE também no $3^{\circ}, 4^{\circ}$ e $5^{\circ}$ ano pós-IPO e um maior MB para as empresas PE no $1^{\circ}, 2^{\circ}$ e $5^{\circ}$. Frank e Goyal (2009) estudam a relação entre debt-to-equity (DE) e MB e concluem que um alto MB tende a gerar uma baixa alavancagem. Neste estudo, considerando-se a amostra total (PE + NPE), a correlação negativa entre estas variáveis só se verifica no $1^{\circ}$ e $2^{\circ}$ ano pós-IPO. Segmentada a amostra em PE e NPE, a conclusão de Frank e Goyal (2009) só se verifica no $1^{\circ} \mathrm{e}$ no $5^{\circ}$ ano pós-IPO, quando as empresas $\mathrm{PE}$ apresentam maior $\mathrm{MB}$ e menor $\mathrm{DE}$ e no $3^{\circ}$ ano pós-IPO, quando as empresas NPE apresentam maior MB e menor DE. Contudo, apenas a diferença das médias entre PE e NPE em MB1 é estatisticamente significante a $5 \%$. 
Tabela 12

Médias das variáveis DE e MB nos cinco anos estudados; resultados para PE e NPE e teste t de diferença de médias

\begin{tabular}{ccccccccccc} 
& DE1 & DE2 & DE3 & DE4 & DE5 & MB1 & MB2 & MB3 & MB4 & MB5 \\
\hline PE & 1,5492 & 0,4031 & 0,5867 & 0,9849 & 0,8635 & 5,6200 & 4,6875 & 4,1524 & 4,2812 & 2,9887 \\
NPE & 2,1950 & 0,3871 & 0,7159 & 1,6150 & 0,8682 & 3,4982 & 4,0596 & 7,2826 & 6,8828 & 2,3944 \\
Teste t & $-0,9004$ & 0,1453 & $-0,6281$ & $-0,5408$ & $-0,02254$ & $1,7418^{* *}$ & 0,4765 & $-0,7753$ & $-0,6891$ & 0,6773 \\
\hline
\end{tabular}

Fonte: Bloomberg. Elaborado pelos autores.

Nota: Teste T de 2 médias; H0: diferença de médias $=0 ; \mathrm{H} 1$ : média $1>$ média 2; amostra média PE-amosta média NPE. ** sig.est a $5 \%$.

Figura 4

Market-to-Book e Debt-to-Equity, anos 1 a 5 pós-IPO

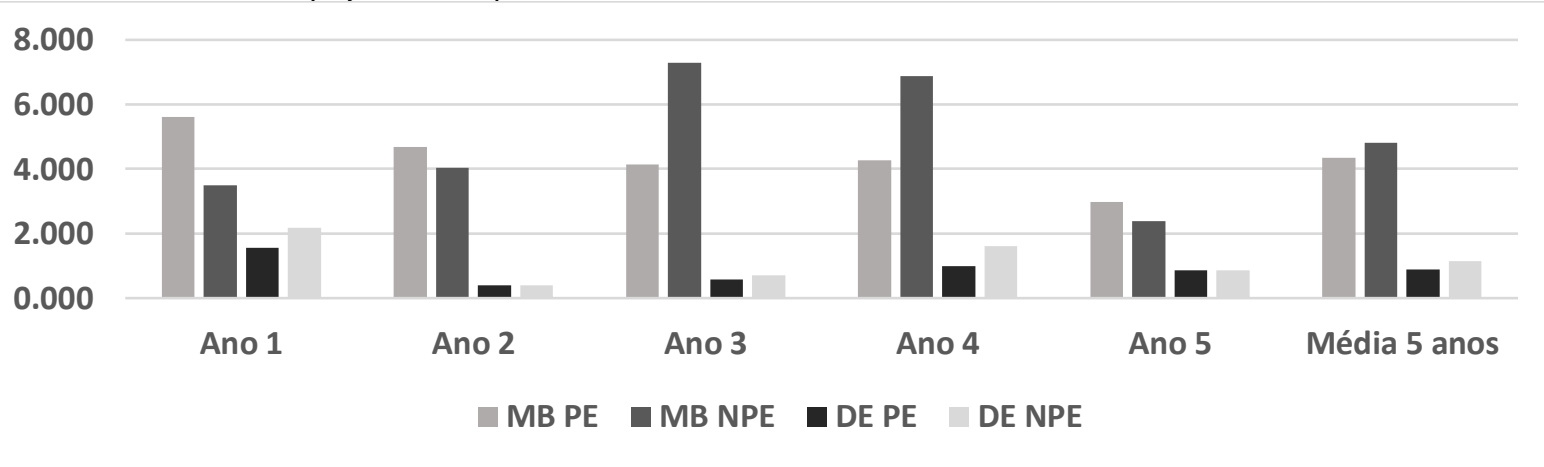

Fonte: Bloomberg. Elaborado pelos autores. 


\subsection{Modelos de regressão utilizados}

As variáveis WR e WRRA são utilizadas como dependentes em regressões cross-section diversas, correspondentes aos anos 1 a 5 pós-IPO. Testa-se a significância estatística da presença do fundo PE para explicar a variação das mesmas. Emprega-se o método dos Mínimos Quadrados Ordinários (MQO), com erros-padrão robustos de White, em regressões independentes para cada um dos cinco anos de retorno coletados. A síntese dos resultados encontra-se nas tabelas 14 a 16 :

Tabela 13

Resultados das regressões (7) e (8) para os 5 anos pós-IPO, método MQO

\begin{tabular}{ccccccccccc}
\hline & WR1 & WRRA1 & WR2 & WRRA2 & WR3 & WRRA3 & WR4 & WRRA4 & WR5 & WRRA5 \\
\hline Const & $0,918032^{* * * *}$ & $1,91883^{* * *}$ & $0,83671^{* * * *}$ & $1,1708^{* * *}$ & $0,91207 * * *$ & $1,2485^{* * * *}$ & $0,91863 * * *$ & $1,0783 * * *$ & $1,0797 * * * 1,2754 * * *$ \\
& $(0,53746)$ & $(0,373472)$ & $(0,074731)$ & $(0,171636)$ & $(0,089004)$ & $(0,2144)$ & $(0,08506)$ & $(0,1448)$ & $(0,1217)$ & $(0,18201)$ \\
$\mathrm{PE}$ & $0,256629 * * *$ & $-0,29065$ & $0,42029 * *$ & $0,501004 *$ & 0,3515 & 0,48374 & 0,40222 & 0,5656 & 0,2438 & 0,3397 \\
& $(0,09154)$ & $(0,6556)$ & $(0,17953)$ & $(0,30041)$ & $(0,19465)$ & $(0,35494)$ & $(0,2456)$ & $(0,3652)$ & $(0,2633)$ & $(0,39914)$ \\
\hline $\mathrm{R}^{2}$ & 0,0055 & 0,00145 & 0,03945 & 0,0202 & 0,0245 & 0,01398 & 0,02207 & 0,01978 & 0,0077 & 0,0065 \\
$\mathrm{R}^{2}$ & & & & & & & & & & \\
ajustado & 0,04803 & $-0,00599$ & 0,03228 & 0,12923 & 0,01701 & 0,00639 & 0,01342 & 0,01119 & $-0,0016$ & $-0,0028$
\end{tabular}

Fonte: Elaborado pelos autores.

Nota: *sig. $10 \%$; **sig. $5 \%$;***sig. $1 \%$. Erros-padrão estão entre parênteses.

Os resultados apontam a significância estatística da variável PE para explicar a variação de WR, de $1 \%$ e 5\%, quando analisada em regressão simples apenas nos dois primeiros anos após o IPO. Pode-se aceitar H3 apenas na regressão simples (7) em WR1. Não se corrobora, então, $H 3$, para os demais períodos, pois não há significância estatística a $1 \%$ para PE nos períodos posteriores estudados. 
Tabela 14

Resultados das regressões (9) e (10) para 1 a 5 anos pós-IPO, método MQO

\begin{tabular}{|c|c|c|c|c|c|c|c|c|c|c|}
\hline & WR1 & WRRA1 & WR2 & WRRA2 & WR3 & WRRA3 & WR4 & WRRA4 & WR5 & WRRA5 \\
\hline Const & $\begin{array}{l}0,9056 * * * \\
(0,294126)\end{array}$ & $\begin{array}{l}5,7349 * * \\
(2,70013)\end{array}$ & $\begin{array}{c}-0,205491 \\
(0,38915)\end{array}$ & $\begin{array}{c}-0,098878 \\
(0,85482)\end{array}$ & $\begin{array}{c}0,501888 \\
(0,5423)\end{array}$ & $\begin{array}{c}0,536178 \\
(0,9658)\end{array}$ & $\begin{array}{l}0,377406 \\
(0,76604)\end{array}$ & $\begin{array}{c}0,368789 \\
(1,1115)\end{array}$ & $\begin{array}{c}1,05078 \\
(0,785916)\end{array}$ & $\begin{array}{c}1,14137 \\
(0,93581)\end{array}$ \\
\hline PE & $\begin{array}{l}0,197206 * * \\
(0,0805158)\end{array}$ & $\begin{array}{l}-0,794551 \\
(0,831513)\end{array}$ & $\begin{array}{c}0,194216 * \\
(0,11042)\end{array}$ & $\begin{array}{c}0,163447 \\
(0,2272)\end{array}$ & $\begin{array}{c}0,157168 \\
(0,1522)\end{array}$ & $\begin{array}{l}0,179787 \\
(0,29452)\end{array}$ & $\begin{array}{l}0,193179 \\
(0,21083)\end{array}$ & & $\begin{array}{c}-0,09436 \\
(0,2179)\end{array}$ & $\begin{array}{l}-0,23703 \\
(0,27528)\end{array}$ \\
\hline SM & $\begin{array}{c}-0,0565764 \\
(0,129823)\end{array}$ & $\begin{array}{c}-1,09876 \\
(0,793206)\end{array}$ & $\begin{array}{c}-0,134563 \\
(0,189459)\end{array}$ & $\begin{array}{c}-0,338591 \\
(0,34878)\end{array}$ & $\begin{array}{c}-0,223382 \\
(0,2852)\end{array}$ & $\begin{array}{l}-0,32792 \\
(0,48327)\end{array}$ & & & $\begin{array}{c}-0,208113 \\
((0,3164)\end{array}$ & $\begin{array}{l}-0,40472 \\
(0,43255)\end{array}$ \\
\hline 1_VOP & $\begin{array}{l}0,0235114 \\
(0,046005)\end{array}$ & $\begin{array}{l}-0,289203 \\
(0,338872)\end{array}$ & $\begin{array}{c}0,16297 * * * * \\
(0,05698)\end{array}$ & $\begin{array}{r}0,23903 * \\
(0,13771)\end{array}$ & $\begin{array}{r}0,0898017 \\
(0,07499)\end{array}$ & $\begin{array}{c}0,165977 \\
(0,1503)\end{array}$ & $\begin{array}{l}0,0340606 \\
(0,103576)\end{array}$ & $\begin{array}{l}0,0686359 \\
(0,14268)\end{array}$ & $\begin{array}{c}0,005514 \\
(0,114572)\end{array}$ & $\begin{array}{c}0,03898 \\
(0,14161)\end{array}$ \\
\hline UN & $\begin{array}{c}2,20182 * * * \\
(0,365755)\end{array}$ & $\begin{array}{l}-1,34299 \\
(4,03019)\end{array}$ & $\begin{array}{c}3,35379 \\
* * * \\
(1,27123)\end{array}$ & $\begin{array}{c}4,51999 * * \\
(1,97021)\end{array}$ & $\begin{array}{c}4,47903^{*} * \\
(2,1621)\end{array}$ & $\begin{array}{r}6,58991 * * \\
(3,14407)\end{array}$ & $\begin{array}{l}4,55744 * \\
(2,6323)\end{array}$ & $\begin{array}{c}7,58372 * * \\
(3,70286)\end{array}$ & $\begin{array}{l}4,38682 * \\
(2,62187)\end{array}$ & $\begin{array}{l}7,94542 * \\
(4,08833)\end{array}$ \\
\hline MB & $\begin{array}{c}0,00291805 \\
(0,005985)\end{array}$ & $\begin{array}{c}0,023588 \\
(0,0423381)\end{array}$ & $\begin{array}{c}0,0944544 \\
* * * \\
(0,01954)\end{array}$ & $\begin{array}{c}0,129834 \\
* * * \\
(0,03350)\end{array}$ & $\begin{array}{c}0,0453197^{* * *} \\
(0,01159)\end{array}$ & $\begin{array}{c}0,107139 \\
* * * \\
(0,04022)\end{array}$ & $\begin{array}{l}0,06 \\
(0,0\end{array}$ & & & \\
\hline $\mathrm{DE}$ & $\begin{array}{c}-0,00248721 \\
(0,008299)\end{array}$ & $\begin{array}{c}0,0824704 \\
(0,0684685)\end{array}$ & $\begin{array}{l}0,0276145 \\
(0,08237)\end{array}$ & $\begin{array}{l}0,198895 \\
(0,20826)\end{array}$ & $\begin{array}{l}0,00617875 \\
(0,0523028)\end{array}$ & $\begin{array}{l}0,037494 \\
(0,08474)\end{array}$ & $\begin{array}{l}-0,01915^{*} \\
(0,010047)\end{array}$ & $\begin{array}{c}-0,016374 \\
(0,01412)\end{array}$ & $\begin{array}{l}-0,13999 \\
(0,15028)\end{array}$ & $\begin{array}{c}-0,284176 \\
(0,22165)\end{array}$ \\
\hline NI & $\begin{array}{c}-2,13864 \mathrm{e}- \\
05^{* * *} \\
(4,93162 \mathrm{e}- \\
06) \\
\end{array}$ & $\begin{array}{c}-0,000159693 \\
* * * \\
(4,98966 \mathrm{e}-05)\end{array}$ & 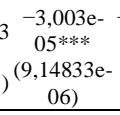 & $\begin{array}{c}-6,45663 \mathrm{e}- \\
05 * * * \\
(1,5403 \mathrm{e}- \\
05)\end{array}$ & $\begin{array}{c}-2,86685 \mathrm{e}- \\
05 * * \\
(1,12752 \mathrm{e}-05)\end{array}$ & $\begin{array}{c}-7,1852 \mathrm{e}- \\
05 * * * \\
(2,05680 \mathrm{e}- \\
05)\end{array}$ & $\begin{array}{c}-1,5071 \mathrm{e}- \\
05 \\
-(1,18007 \mathrm{e}- \\
05)\end{array}$ & $\begin{array}{c}-4,109 \mathrm{e}- \\
05^{* *} \\
(1,7679 \mathrm{e}- \\
05)\end{array}$ & $\begin{array}{c}-1,85926 \mathrm{e}- \\
05 \\
(1,33171 \mathrm{e}- \\
05)\end{array}$ & $\begin{array}{c}-3,66752 \mathrm{e}- \\
05 \\
(1,923882 \mathrm{e}- \\
05)\end{array}$ \\
\hline $\mathrm{R}^{2}$ & 0,3708 & 0,103827 & 0,620047 & 0,430549 & 0,377272 & 0,346552 & 0,335211 & 0,385987 & 0,368482 & 0,501005 \\
\hline $\begin{array}{c}\mathrm{R}^{2} \\
\text { ajust }\end{array}$ & 329637 & 0,045199 & 0,596300 & 0,394958 & 0,33728 & 0,304587 & 0,286737 & 0,341216 & 0,318813 & 0,461758 \\
\hline
\end{tabular}

Fonte: Elaborado pelos autores.

Nota: *sig. $10 \%$; **sig. $\% \% ; * *$ sig. $1 \%$. Erros-padrão estão entre parênteses.

No modelo da equação (9), PE apresenta significância estatística de $5 \%$ apenas em WR1 e de 10\% em WR2. Isto sugere que, após dois anos da oferta pública, o "efeito PE" não é mais estatisticamente significante para explicar os retornos relativos apurados pela ação da empresa em mercado. Contudo, no modelo ampliado, outras variáveis mostram-se com maior significância estatística para explicar os WR pós-IPO, como UN (1\% em WR1 e WR2), 1_VOP (1\% em WR2), MB (1\% em WR2, WR3 e WR5) e NI ( $1 \%$ em WR1 e WR2).

Ponderando-se os retornos relativos em relação ao benchmark pelo risco individual da ação (WRRA), a significância estatística da variável PE aparece a $10 \%$ apenas em WRRA2, no modelo da regressão (8) e desaparece em todos os anos após o IPO, no modelo completo da equação (10). Todavia, ao se incluir o beta da ação após o IPO, outras variáveis emergem com maior significância estatística para explicar WRRA: NI (1\% em WRRA1 a WRRA3), MB (1\% em WRRA2, WRRA3 e WRRA5). DE e SM não apresentam significância estatística em nenhum modelo testado 
e 1_VOP, apenas 10\% em WRRA2. Na média, os WRRA de empresas PE superam os de NPE em 4 dos 5 anos estudados, mas não se pode corroborar $H 2$, pois a diferença entre as médias dos dois grupos não se revelou estatisticamente significante a 1\%, em nenhum período após o IPO. Os resultados não apontam a significância estatística da variável $\mathrm{PE}$ na explicação da variação de WRRA, em nenhum modelo de modo que não se pode corroborar $H 3$, para os retornos das ações, quando ponderados pelo risco idiossincrático.

Nos modelos econométricos desenvolvidos, outras variáveis, tais como UN, NI, 1_VOP e MB emergem com significância estatística maior para explicar WR. Considerando-se o risco individual da ação, NI e MB possuem a maior significância estatística para explicar o WRRA, nos períodos pós-IPO. O nível de Governança Corporativa da empresa, representado por SM e a alavancagem, calculada por DE, são variáveis explicativas que não mostraram significância estatística de $1 \%$ em nenhum modelo testado.

Os resultados surpreendem de diversas maneiras. Primeiro, por contrariar estudos similares que encontram significância estatística para a variável PE a 1\% em modelos ampliados (Minardi et al, 2013; Levis, 2011); segundo, por mostrar significância estatística, nos anos posteriores ao IPO, às variáveis UN e NI, um efeito prolongado no tempo de duas típicas variáveis com efeitos de curto prazo; terceiro, por indicar que as proxies para alavancagem da empresa (DE) e nível de Governança Corporativa (SM) não são estatisticamente significantes para explicar as variações dos retornos das ações de empresas que abriram capital após 2004, sejam eles ponderados ou não pelo risco idiossincrático. Considerando-se DE como uma proxy para a estrutura de capital da empresa tem-se que esta não é estatisticamente significante para explicar o Wealth Relative da ação, conclusão que remete à proposição I de Modigliani e Miller (1958), a qual preceitua que a estrutura de capital escolhida pela empresa é irrelevante para gerar valor ao acionista; quinto, por indicar que 1_VOP não é estatisticamente significante no $1^{\circ}$ ano pósIPO e sim no ano seguinte (WR2), contrariando Jain e Kini (1995), Kaplan e Schoar (2005) e Minardi et al (2013) e; sexto, pois, ao se considerar o risco (WRRA), as variáveis explicativas utilizadas apresentam diferentes significâncias estatísticas em relação à variável dependente, modificandose os resultados em relação aos diversos modelos sem risco até então estudados em artigos similares. 


\section{Conclusões}

Este trabalho propôs-se a estudar se as ações de empresas investidas por fundos PE obtém um retorno relativo maior se comparadas às ações de empresas sem estes investidores prévios (NPE), a partir da data do IPO. Os retornos relativos (Wealth Relative, WR) foram calculados sobre o Índice Bovespa, em periodicidade anual, a partir das datas de suas respectivas ofertas públicas de ações. A contribuição deste artigo à literatura do tema está em considerar na análise do retorno, o risco idiossincrático do ativo, analisando também a relação risco-retorno após o IPO. Para tanto, inovase ao se ponderar a fórmula Wealth Relative Buy-and-Hold de Ritter (1991), Brav e Gompers (1997) e Cao e Lerner (2009) ao risco da ação, medido pelo seu coeficiente beta. Apura-se assim, o Wealth Relative Risk Adjusted (WRRA), na mesma periodicidade anual pós-IPO. O período de coleta de dados das variáveis utilizadas abrange de maio de 2004 a setembro de 2016, com um total de 136 empresas, as quais abriram capital entre os anos de 2004 e 2014.

Nos modelos econométricos desenvolvidos, nota-se que o efeito PE como responsável pelos maiores retornos relativos pós-IPO não perdura após o segundo ano subsequente à abertura de capital. Quando ponderados os retornos pelo risco, PE não se mostra estatisticamente significante em nenhum período. Outras variáveis emergem para explicar WR e WRRA com maior significância estatística do que PE. Considerando-se o risco individual da ação, NI e MB possuem a maior significância estatística para explicar o WRRA, nos períodos pós-IPO. O nível de Governança Corporativa da empresa, representado por SM e a alavancagem, calculada por DE, todavia, não mostraram significância estatística de $1 \%$ em nenhum modelo testado.

Para as próximas pesquisas acerca do tema, os autores sugerem que, dada a limitação natural do número de empresas nacionais, testem-se amostras maiores, obtidas em mercados internacionais e em períodos diversos para verificar se as conclusões e resultados ponderados pelo risco aqui propostos se mantém.

\section{Referências}

ABVCAP- ASSOCIAÇÃO BRASILEIRA DE PRIVATE EQUITY E VENTURE CAPITAL. Dados da Indústria de Private Equity e Venture Capital 2011-2012. Disponível em http://www.abvcap.com.br/Download/Estudos/2003.pdf. 
Assaf Neto, Alexandre. 2015. Mercado Financeiro, $13^{\mathrm{a}}$ edição, São Paulo, Editora Atlas S.A.

Axelson, Ulf; Stromberg, Per; \& Weisbach, Michael S. 2009. Why are Buyouts Levered? The Financial Structure of Private Equity Funds. The Journal of Finance, 64, 1549-1582. Doi: http://doi/10.1111/j.1540-6261.2009.01473.x/full.

Barry, Chistopher B.; Muscarella, Chris J; Peavey, John; \& Vetsuypens, Michael R. 1990. The role of venture capital in creation of public companies. Evidence from the going-public process. Journal of Financial Economics, 27, 447-471. http://10.1016/0304405x(90)90064-7.

Bastos, Ricardo M.P.; Pinto, Antonio C.F.; Klotze, Marcelo C.; \& Silva, Paulo Vitor J.G. 2016. Fundos de Investimento e Desempenho PósIPO no Brasil. Revista Pensamento Contemporâneo em Administração, 10, 134-151. Doi: http://dx.doi.org/10.12712/rpca.v10i3.648.

Bodie, Zvi; Kane, Alex; Marcus, Alan, J. 2014. Investments, 10a. edition. McGraw-Hill Education, New York, NY, USA.

Boulton, Thomas J.; Smart, Scott B.; \& Zutter, Chad J. 2011. Earnings Quality and International IPO Underpricing. The Accounting Review, 86, Issue 2, Doi: http://dx.doi.org/10.2308/accr.00000018.

Brav, Alon; Gompers, Paul A. 1997. Myth or Reality? The Long-Run Underperformance of Initial Public Offerings: Evidence From Venture and Nonventure Capital-Backed Companies. The Journal of Finance, 52, n. 5. Doi: http://doi:10.1111/j.15406261.1997.tb02742x.

Brealey, Richard A.; Myers, Stewart C.; \& Allen, Franklin. 2014. Principles of Corporate Finance, 11a edition, McGraw- Hill Education, ISBN: 139780077151560.

Cao, Jerry; \& Lerner, Josh. 2009. The Performance of Reverse Leveraged Buyouts. Journal of Financial Economics, 92, 139-157. Doi: http://dx.doi.org/10.1016/j.fineco.2008.03.002.

Chambers, David; \& Dimson, Elroy. 2009. IPO Underpricing over the Very Long Run. The Journal of Finance, 64, 1407-1443. Doi: http://10.1111/j.1540-6261.2009.01468.x.

Chemmanur, Thomas J.; \& Loutskina, Elena. 2005. The Role of Venture Capital Backing in Initial Public Offerings: Certification, Screening 
or Market Power?, EFA 2005 Moscow Meetings Paper. Doi: http://dx.doi.org/10.2139/ssrn.604882.

Ellul, Andrew; \& Pagano, Marco. 2006. IPO Underpricing and AfterMarket Liquidity. The Review of Financial Studies, 19, 381-421. Doi: http://10.1093/rfs/hhj018.

Engel, Dirk. 2002. The Impact of Venture Capital on Firm Growth: An Empirical Investigation. Centre for European Economic Research. Discussion Paper n.02-02, Mannhein, Doi: http://dx.doi.org/10.2139/ssrn.319322.

Fama, Eugene F.; \& French, Kenneth R. 1993. Common risk factors in the returns on stock and bonds. Journal of Financial Economics, 33, 356. Doi: http://10.1016/0304-405X(93)90023-5.

Ferrari, Guilherme, L.; \& Minardi, Andrea M.A.F. 2010. O Desempenho de Ofertas Públicas Iniciais de Empresas Brasileiras Financiadas por Fundos de Private Equity. Insper Working Paper,WPE: 224/2010.

Folta, Timothy B.; \& Janney, Jay J. 2004. Strategic benefits to Firms Issuing Private Equity Placements. Strategic Management Journal, 25. 223-242. Doi: http://10.1002/smj.373.

Frank, Murray Z.; \& Goyal, Vidhan K. 2009. Capital Structure Decisions: Which Factors are Reliably Important? Financial Management, 1-37. Doi: http://10.1111/j.1755-053X.2009.01026.x.

Gompers, Paul. 1995. Optimal Investment, Monitoring, and the Staging of Venture Capital. The Journal of Finance, 50, 1461-1489. Doi: http://10.1111/j.1540-6261.1995.tb05185.x.

Gompers, Paul; \& Lerner, Josh. 2001. The Venture Capital Revolution. The Journal of Economic Perspectives, 15, 145-168. Doi: http://10.1257/jep.15.2.145.

Gompers, Paul; \& Lerner, Josh. 2003. The Really Long-run Performance of Initial Public Offerings: The Pre-Nasdaq Evidence. The Journal of Finance, 58, 1355-1392. Doi: http://10.1111/1540-6261.00570.

Hochberg, Yael V. 2012. Venture Capital and Corporate Governance in the Newly Public Firm. Review of Finance, 16, 429-480. Doi: http://10.1093/rof/rfr035.

Jain, Barat A.; \& Kini, Omesh. 1995. Venture Capitalist Participation and the Post-issue Operating Performance of IPO Firms. Managerial and Decision Economics, 16, 593-606. Doi: http://10.1002/mde.4090160603. 
Kaiser, Kevin; \& Westarp, Christian. 2010. Value Creation in the Private Equity and Venture Capital Industry. Insead Working Papers, Social Science Research Network, SSRN. Doi: http://dx.doi.org/10.2139/ssrn.1592325.

Kaplan, Steven N.; \& Schoar, Antoinette. 2005. Private Equity Performance: Returns, Persistence, and Capital Flows. The Journal of Finance, 60, 1791-1823. Doi: http://10.1111/j.1540-6261. 2005.00780.x.

Kerins, Frank; Smith, Janet K.; \& Smith, Richard. 2004. Opportunity Cost of Capital for Venture Capital Investors and Entrepreneurs. The Journal of Financial and Quantitative Analysis, 39, 385-405. Doi: https://doi.org/10.1017/S0022109000003124.

Lee, Peggy. M.; \& Wahal, Sunil. 2002. Grandstanding, Certification and the Underpricing of Venture Capital Backed IPOs. Journal of Financial Economics, 73, 375-407. Doi: http://dx.doi.org/10.1016/j.fineco.2003.09.003.

Leone, Andrew J.; Rock, Steve; \& Willenborg, Michael. 2007. Disclosure of Intended Use of Proceeds and Underpricing in Initial Public Offerings. Journal of Accounting Research, 45, 111-153. Doi: http://10.1111/j.1475-679X.2006.00229.x.

Levis, Mario. 2011. The Performance of Private Equity-Backed IPOs. Financial Management, 40. Doi: http://10.1111/j.1755053X.2010.01141.x.

Lintner, John. 1965. The valuation of risk assets and the selection of risky investments in stocks portfolio and capital budgets. Review of Economics and Statistics, 47, 13-37. Doi: http://10.2307/1924119.

Megginson, William L.; \& Weiss, Kathleen A. 1991. Venture Capitalist Certification in Initial Public Offerings. The Journal of Finance, 46, 879-903. Doi: http://10.1111/j.1540-6261.1991.tb03770.x.

Minardi, Andrea M.A.F.; Ferrari, Guilherme L; \& Tavares, Pedro C.A. 2013. Perfomances of Brazilian IPOs backed by private equity. Journal of Business Research, 66, 448-455. Doi: http://dx.doi.org/10.1016/j.busres.2012.04.012.

Minardi, Andrea M.A.F.; Moita, Rodrigo M.; \& Castanho, Rafael P. 2015. Investigating the partial adjustment effect of Brazilian IPOs. Journal of Business Research, 68, 189-198. Doi: http://dx.doi.org/10.1016/j.busres.2014.09.027. 
Modigliani, Franco; \& Miller, Merton H. 1958. The Cost of Capital, Corporation Finance and the Theory of Investment. The American Economic Review, 48, 261-297. http://www.jstor.org/stable/1809766.

Morsfield, Suzanne G.; \& Tan, Cristine E.L. 2006. Do Venture Capitalists Influence the Decision to Manage Earnings in Initial Public Offerings?. The Accounting Review, 81, 1119-1150. Doi: http://dx.doi.org/10.2308/accr2006.81.5.1119.

Ogden, Joseph P.; Jen, Frank C.; \& O’Connor, Philip F. 2003. Advanced Corporate Finance - Policies and Strategies. Prentice Hall, New Jersey.

Ritter, Jay R. 1991. The Long-Run Performance of Initial Public Offerings. The Journal of Finance, 46, n. 1. Doi: http://10.1111/j.15406261.1991.tb03743.x.

Ross, Stephen A.; Westerfield, Randolph W.; Jaffe, Jeffrey. Lamb, Roberto (2015) Administração Financeira, versão brasileira de Corporate Finance, 10th edition, AMGH Editora, Porto Alegre, RS; McGraw-Hill New York, NY, USA.

Scholes, Louise; Wright, Mike; Westhead, Paul; Bruining, Hans; \& Kloeckner, Olivier. 2009. Family-Firm Buyouts, Private Equity, and Strategic Change. The Journal of Private Equity, 12, 7-18. Doi: http://dx.doi.org/10.2139/ssrn2002893.

Sharpe, William F. 1964. Capital asset prices: A theory of market equilibrium under condition of risk. The Journal of Finance, 19, 425442. Doi: http://10.1111/j.1540-6261.1964.tb02865.x.

Silva, José M.A; Famá, Rubens. 2011. Evidências de retornos anormais nos processos de IPO na Bovespa no período 2004-2007: um estudo de evento. Revista de Administração- RAU-USP, 46, 178-190. Doi: http://dx.doi.org/10.570/rauusp1006.

Tavares, Pedro C.A.; \& Minardi, Andrea M.A.F. 2010. Does Private Equity Investment Work as a Quality Certification for IPOs in Brazil? Disponível em http://ssrn.com/abstract=1624876.

Welch, Ivo. 2004. Capital Structure and Stock Returns. Journal of Political Economy, 112, 106-131. Doi: http://dx.doi.org/10.1086/379933. 